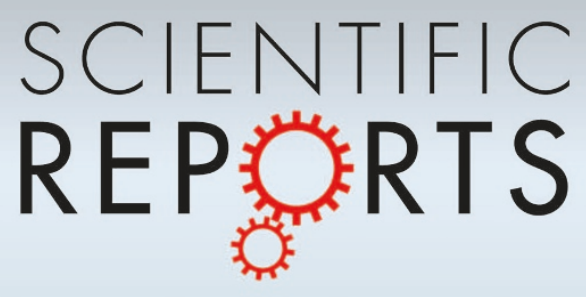

OPEN

SUBJECT AREAS:

INFLAMMATION

BACTERIAL INFECTION

LYMPHOCYTE ACTIVATION

Received

18 October 2013

Accepted

10 March 2014

Published

27 March 2014

Correspondence and requests for materials should be addressed to M.S.A. (Mohammad. alam@fda.hhs.gov)

\section{Ecto-5'-Nucleotidase (CD73) Regulates Host Inflammatory Responses and Exacerbates Murine Salmonellosis}

\author{
M. Samiul Alam' ', Jennifer L. Kuo' , Peter B. Ernst² ${ }^{2}$ Victoria Derr-Castillo², Marion Pereira', Dennis Gaines', \\ Matthew Costales', Elmer Bigley' \& Kristina Williams'
} 'Immunobiology Branch, Office of Applied Research and Safety Assessment, Center for Food Safety and Applied Nutrition, US Food
and Drug Administration, Laurel, MD 20708, ²Division of Comparative Pathology and Medicine, University of California, San
Diego, 9500 Gilman Drive, MC 0612, San Diego, CA 92093-0612.

Food-borne Salmonella spp., are a major cause of hospitalization and death. Adenosine, an important immune regulator of inflammation, limits tissue damage during infection. CD39 (nucleoside triphosphate dephosphorylase) combined with ecto-5' ${ }^{\prime}$-nucleotidase (CD73) metabolizes ATP to adenosine. We studied the expressions of CD39 and CD73 in tissues, and T helper cells in mice after Salmonella infection and evaluated the role of CD73 in regulating immune responses and bacterial clearance in wild-type and CD73-deficient $\left(\mathrm{CD}^{2} 3^{-1-}\right)$ mice. Both CD39 and CD73 transcript levels declined in the infected wild-type mice. Compared to wild-type mice, tissues from infected $\mathrm{CD}^{-1-}$ mice had significantly higher expression of pro-inflammatory cytokines and reduced anti-inflammatory responses. $\mathrm{CD} 73^{-1-}$ mice were more resistant to infection and had a greater inflammatory responses and a significantly lower bacterial load in the liver compared to wild-type mice. Thus, CD73 expression attenuates inflammation during murine Salmonellosis and impairs immunity, leading to increased bacterial colonization and prolonged infection.

T

he enterobacterial Salmonella species are a significant cause of morbidity and mortality among human populations ${ }^{1}$. In the United States, nontyphoid Salmonella spp. is the leading cause of hospitalization and death, accounting for an estimated 1.0 million food-borne illnesses annually ${ }^{2}$. Among the immunocompetent population, Salmonella generally remain localized to the intestine, causing a self-limiting gastroenteritis. In immunosuppressed individuals (e.g., pregnant women and HIV-patients), however, Salmonella can lead to bacteremia and death.

Salmonella enterica serovar Typhimurium (ST) is a leading cause of bacterial gastroenteritis in humans, and in susceptible strains of mice it produces murine Salmonellosis, which is characterized by progressive multiple microabscess formations and septicemia ${ }^{3}$. Numerous studies have investigated immunity to Salmonella in mice because this model mimics many important features of human Salmonellosis or Typhoid fever ${ }^{4}$.

Unlike other Gram-negative bacteria (e.g., Neisseria meningitidis, and Haemophilus influenza) that mainly cause acute infection and elicit strong systemic symptoms after tissue invasion, Salmonella infection causes a blunted early immune response that is believed to facilitate long-term survival of the pathogen ${ }^{5}$. A dampened inflammatory response to systemic Salmonella infection would reduce immune-mediated damage to host tissues $^{6}$. In addition to the innate host responses generated by phagocyte oxidase ${ }^{7,8}$ and inducible nitric oxide synthase (iNOS) $)^{3,7-9}$, the initiation of a robust Th1 response is necessary for protective immunity ${ }^{10-12}$. In the mouse model of typhoid, clearance of ST requires the production of IFN- $\gamma$ by CD4 T cells ${ }^{13}$, which have an important role in amplifying inflammatory responses induced in the gut ${ }^{14}$. At the same time, the balance between $\mathrm{T}$ effector and regulatory $\mathrm{T}$ (Treg) cell responses is crucial to clear the bacteria from infected tissue ${ }^{13,15,16}$.

Adenosine is a purine nucleoside implicated in the control of the host response to infection ${ }^{17-20}$. Adenosine accumulates in inflamed or hypoxic tissues largely due to the action of CD39 (nucleoside triphosphate dephosphorylase) mediating the dephosphorylation of ATP to ADP and then to $5^{\prime}$-AMP, the substrate for CD73 (ecto$5^{\prime}$-nucleotidase), which catalyzes the terminal reaction to convert $5^{\prime}$-AMP to adenosine ${ }^{21,22}$. The numerous responses controlled by adenosine are mediated by four G-protein-coupled receptors $\left(A_{1}, A_{2 A}, A_{2 B}\right.$, and $\left.A_{3}\right)^{21,23}$. Activation of $A_{2 A}$ adenosine receptor $\left(A_{2 A} A R s\right)$ on T cells produces a series of anti-inflammatory responses $^{21}$. Recent studies showed that Treg cells express CD39 and CD73 and their presence enhances Treg cell function through the production of adenosin $e^{24-26}$. Other studies have suggested that $\mathrm{CD} 4^{+} / \mathrm{CD} 25^{+} / \mathrm{Foxp}^{+}$ 
Treg cells regulate inflammation and contribute to the persistence of Helicobacter pylori infections ${ }^{18,27}$. Depletion of $\mathrm{CD} 4^{+} \mathrm{CD} 25^{+}$Treg cells enhances effector $\mathrm{T}$ cell activation and reduces pathogen burden during Leishmania major infection ${ }^{28}$. Similarly, other reports suggest a correlation between the increased persistence of Plasmodium falciparum with upregulation of TGF- $\beta 1$, Foxp 3 , and $\mathrm{CD} 4{ }^{+} \mathrm{CD} 25^{+}$Treg cells during human malaria infection ${ }^{29}$. We recently reported the important role of CD73 in modulating Th cell responses and $H$. pylori persistence ${ }^{30}$. Little is known, however, about the role of adenosine in controlling the host response to infection with Salmonella species. In the present study, we examined the expression of CD39 and CD73 in tissues and Th cells, including Treg cells, during murine Salmonella infection and evaluated the role of CD73 in regulating inflammation and bacterial burden using CD73-deficient mice.

\section{Results}

Regulation CD39 and CD73 expression following Salmonella infection. CD39 and CD73 transcript levels are upregulated during hypoxia and inflammation ${ }^{31}$, however, little is known about mRNA or protein expression in response to infection. Following oral Salmonella challenge in wild-type $(\mathrm{C} 57 \mathrm{BL} / 6)$ mice, the mRNA transcript levels of CD39 and CD73 sharply decreased in the liver and spleen (Fig. 1a, b). Similar decrease was also documented in the intestine (Fig. 1c). Recent evidence suggests the involvement of CD39 and CD73 in the control of CD4 ${ }^{+}$Th function ${ }^{24,32,33}$. We therefore examined the surface expression of CD39 and CD73 in splenocytes after Salmonella whole cell lysate (WCL) treatment. Both CD39 and CD73 were abundantly expressed by uninfected or resting splenocytes and $\mathrm{CD}^{+}$Th cells (Fig. 1d, e). Expression of both CD39 and CD73 was decreased in lymphocytes and CD4 ${ }^{+}$Th cell populations when splenocytes were treated with Salmonella WCL (Fig. 1d, e, f). Taken together, these data suggest that murine tissues and Th cells express CD39 and CD73 to generate adenosine locally, and Salmonella infection leads to significant downregulation in both CD39 and CD73 expression.

Inhibition of CD73 enzymatic activity augments pro-inflammatory responses. To examine the contribution of CD73 to cytokine levels during Salmonella infection, murine splenocytes were treated with Salmonella-WCL in the absence or presence of APCP. SalmonellaWCL treatment increased the intracellular cytokines IL17A and IFN- $\gamma$ in splenocyte populations and CD4+ cells and their expression was significantly augmented by CD73-inhibition (Fig. 2). Similarly, increased levels of IFN- $\gamma$ and IL17A were found in culture supernatants of Salmonella-WCL treated splenocytes, and after CD73 inhibition by APCP treatment these cells (Supplementary data: Fig. S1) produced significantly higher levels of the cytokines. Thus, in vitro CD73-inhibition increases Salmonella-WCL induced expression of pro-inflammatory cytokines. Since $5^{\prime}$-AMP is cleaved by CD73 to generate extracellular adenosine; the specificity of CD73 with APCP was tested by measuring the pro-inflammatory cytokines in the supernatant from culture of Salmonella-WCL treated splenocytes in presence of $5^{\prime}$-AMP with or without APCP (Fig. S1c). Addition of $5^{\prime}$-AMP in the culture suppressed the proinflammatory cytokines and, which was partially reversed by the addition of APCP. This, functional assay provided evidence that, splenocytes expressing CD73 generate adenosine that suppresses pro-inflammatory cytokines. It is known that adenosine acts via adenosine receptors expressed by immune and inflammatory cells that are upregulated upon activation ${ }^{21,23}$. Salmonella infected spleen tissues express more $\mathrm{A}_{2 \mathrm{a}} \mathrm{AR}$ mRNA than $\mathrm{A}_{2 \mathrm{~b}} \mathrm{AR}$ (data not shown). To find if adenosine receptors were mediating the changes in cytokine responses, NECA, a non-selective adenosine agonist, was tested by measuring the pro-inflammatory cytokines in the supernatant from the culture of Salmonella-WCL-treated splenocytes in presence or absence of ZM241385, an $\mathrm{A}_{2 \mathrm{a}} \mathrm{AR}$ antagonist (Fig. S1d).
NECA suppressed the pro-inflammatory cytokines induced by STWCL treatment and which was partially abrogated by the addition of ZM241385, confirming that the effect could be also mediated through adenosine receptors. These data confirm that extracellular adenosine produced by CD73 can act via adenosine receptors.

CD73-Deficient mice exhibited increased inflammatory responses following infection. To further investigate the role of CD73 in the control of inflammation in infected mice, we evaluated cytokine expression from splenocytes populations and $\mathrm{CD}^{+} \mathrm{Th}$ cell populations of the infected wild-type and $\mathrm{CD}^{-1-}$ mice. Higher levels of intracellular pro-inflammatory cytokines, such as IFN- $\gamma$, and IL17A, were observed in splenocytes isolated from the infected $\mathrm{CD}_{7}{ }^{-1-}$ mice than in those isolated from wild-type infected mice (Fig. 3c, d). Similarly, responses at the transcript level for IFN- $\gamma$ and IL17A were significantly higher in spleens from infected CD73 ${ }^{-1-}$ mice (Fig. 3a, b).

Histologic examination of the liver 8 days post infection revealed mild to moderate hepatic damage in both strains. The liver from the $\mathrm{CD}_{73^{-1-}}$ mice exhibited moderately more inflammation, with aggregates of lymphocytes and macrophages extending to multiple foci throughout the parenchyma, and occasionally surrounded by small numbers of neutrophils (Fig. 4). Rarely within these areas, small foci of necrosis were observed. In both strains, there was evidence of hepatocellular injury accompanied by vesiculation, Kupffer cells swelling and edema, however the inflammatory infiltrate in the wild-type mice liver was less pronounced and centered around portal tracts. The liver tissues from $\mathrm{CD}_{73^{-1-}}$ mice also had significantly higher mRNA expression for the pro-inflammatory cytokines (IFN$\gamma$, TNF- $\alpha$, IL-1 $\beta$ ) and inducible nitric oxide synthase (iNOS) (Fig. 4c). These findings indicate that the number of inflammatory-foci and pro-inflammatory responses in the liver were significantly increased in the absence of CD73 expression, consistent with the increased Th responses in the spleen (Fig. 3).

Anti-inflammatory responses following Salmonella infection. We next examined $\mathrm{CD} 4{ }^{+} \mathrm{CD} 25^{+}$Treg cell subsets and their expression of CD39 and CD73 cells after infection (Supplementary data, Fig. S2). Salmonella infection slightly increased the percentage of Treg cells $\left(\mathrm{CD} 4^{+} \mathrm{CD} 25^{+}\right)$in wild-type and $\mathrm{CD}_{73^{-1-}}$ mice while the percentage Treg expressing CD73 decreased significantly (Supplementary data, Fig. S 2c) after infection. Following infection of $\mathrm{CD} 73^{-1-}$ mice, in the absence of $\mathrm{CD}_{73^{+}}$cells, Treg cells from these mice may not function properly. A previous report indicated that $\mathrm{CD}_{73^{-1-}}$ mouse-derived Treg cells are functionally deficient in regulating $\mathrm{T}$ effector cells ${ }^{24}$. Evaluation of splenic tissue and splenocytes for anti-inflammatory cytokine expression revealed no significant upregulation of IL-10 in infected $\mathrm{CD}_{73^{-1-}}$ mice compared with infected wild-type mice (Fig. 5). Moreover, IL-4, TGF- $\beta 1$ and IL- 13 mRNA response, which is also involved in regulating anti-inflammatory responses by the Treg cells, was significantly reduced in the infected $\mathrm{CD} 73^{-1-}$ mice.

CD73-deficient mice are more resistant to Salmonella infection than wild-type $\left(\mathrm{CD}^{+/+}\right)$mice. Since inhibition of CD73 by APCP enhanced cytokine responses following stimulation with SalmonellaWCL, the role of CD73 in the host response to infection was examined in $\mathrm{CD}_{73}^{-1-}$ mice. Both wild-type and $\mathrm{CD}^{-1-}$ mice were infected with variable doses of Salmonella, and body-weight was monitored. Wild-type mice lost significantly more bodyweight than $\mathrm{CD}^{-1-}$ mice following oral infection with $1 \times$ $10^{6} \mathrm{CFU} /$ mice (Fig. 6). With an oral infective dose of $1 \times$ $10^{7} \mathrm{CFU}$, both groups of mice became sick, but CD73-deficent mice lost relatively less body weight than infected wild-type mice. In fact, throughout the Salmonella infection experiments, we observed that significantly more ST-infected wild-type mice displayed severe clinical signs than CD73-deficient mice (Supplementary data, S3, Table). 
a

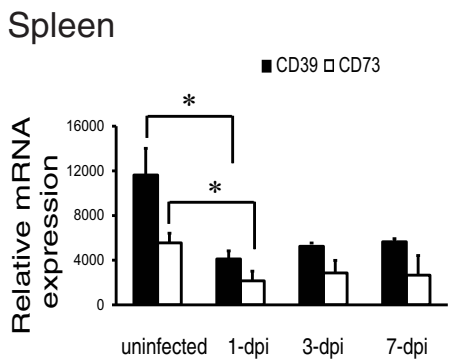

b

Liver

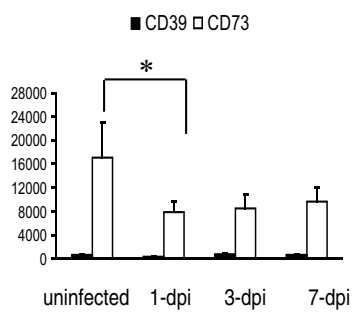

C

Intestine

- $C D 39 \square C D 73$

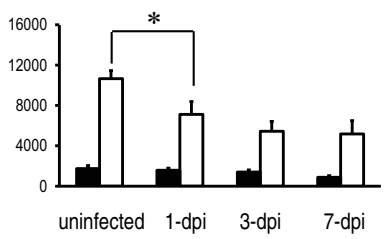

d

\section{Untreated resting splenocytes}
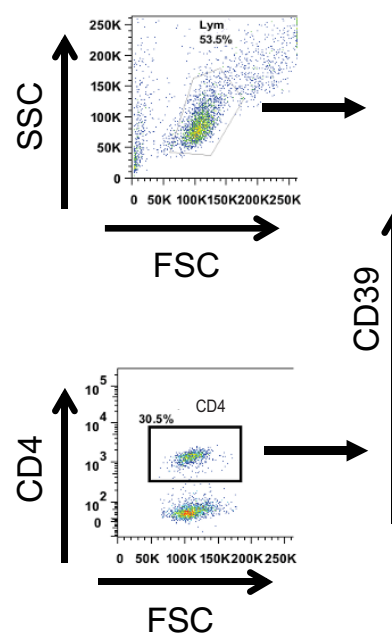

FSC

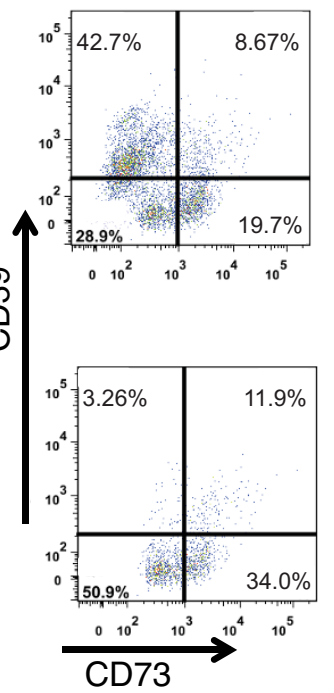

e

\section{ST WCL-treated splenocytes (24h)}

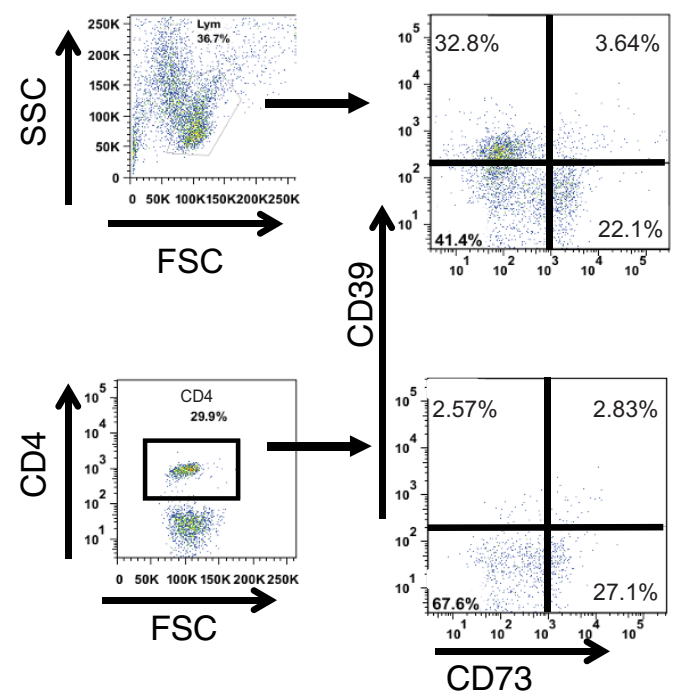

f

- Unstimulated and resting

- ST WCL activated: $24 \mathrm{~h}$
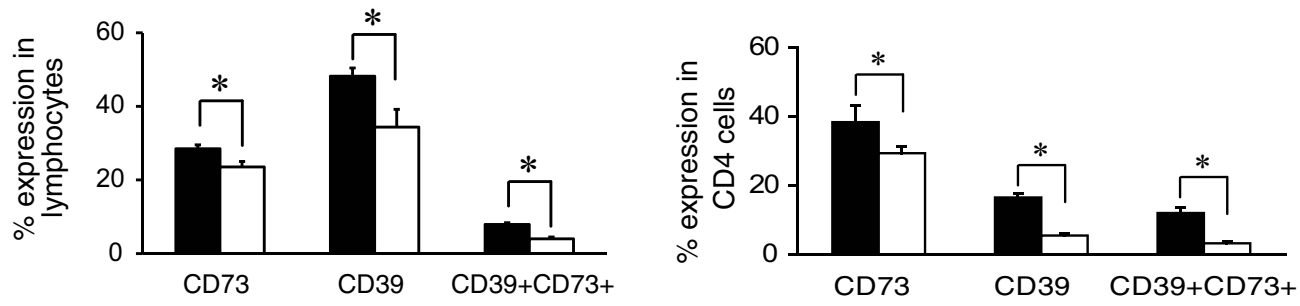

Figure 1 Downregulation of CD73 expression following Salmonella infection. Relative mRNA expression of CD39 and CD73 in splenic (a) and hepatic (b), and intestinal (c) tissues after oral infection with $1 \times 10^{6} \mathrm{CFU}$ of Salmonella enterica serotype Typhimurium (ST) LT-2 strain. (d), Expression of surface apyrases (CD39) and ecto-5' -nucleotidase (CD73) in control (untreated resting) (d, left panel) and ST whole-cell Lysate (WCL) (35 $\mu \mathrm{g} / \mathrm{ml})$ treated $(24 \mathrm{~h})\left(\mathrm{e}\right.$, right panel) splenocytes and $\mathrm{CD} 4^{+}$helper T cells. Control and treated cells were stained with FITC-conjugated anti-mouse CD4 ${ }^{+}$, PE conjugated anti-mouse CD73, and pE-Cy7-conjugated anti-mouse CD39. Splenocytes were gated on forward (FSC) versus side scatter (SSC) and then analyzed for CD39 and CD73 or analyzed for forward scatter (FSC) versus CD4 ${ }^{+}$and again analyzed for CD39 and CD73. Summary graph (f) showing the distribution of CD39 and $\mathrm{CD} 73$ and $\mathrm{CD} 39^{+} \mathrm{CD}_{3}{ }^{+}$cells in the gated lymphocytes and gated $\mathrm{CD} 4{ }^{+} \mathrm{Th}$ splenocytes. Percentile values in each bar represent the mean from the splenocytes of 3-4 mice analyzed by multi-color FACS staining and show the enrichment of Th cells that express both CD39 and CD73. Data shown are the mean \pm SEM from one independent experiment performed at least three times using $3-4$ mice. ${ }^{*}, p<0.05$.

CD73 gene deletion enhances clearance of Salmonella from infected tissues. Since CD73 gene deletion in mice confers resistance against ST infection and causes significantly enhanced pro-inflammatory responses in these tissues, we hypothesized that the adenosine-mediated regulation of Th cells would contribute to Salmonella persistence. To investigate this, an in vivo Salmonella infection study was conducted. Salmonella colonization in the liver was significantly lower in the $\mathrm{CD}_{7} 3^{-1-}$ mice than in the wild-type mice (Fig. 7). A separate infection experiment using a lower infection dose to evaluate long-term Salmonella colonization 20 days after infection revealed that $\mathrm{CD} 73^{-1-}$ mice effectively cleared most of the Salmonella, while wild-type mice had significantly higher 


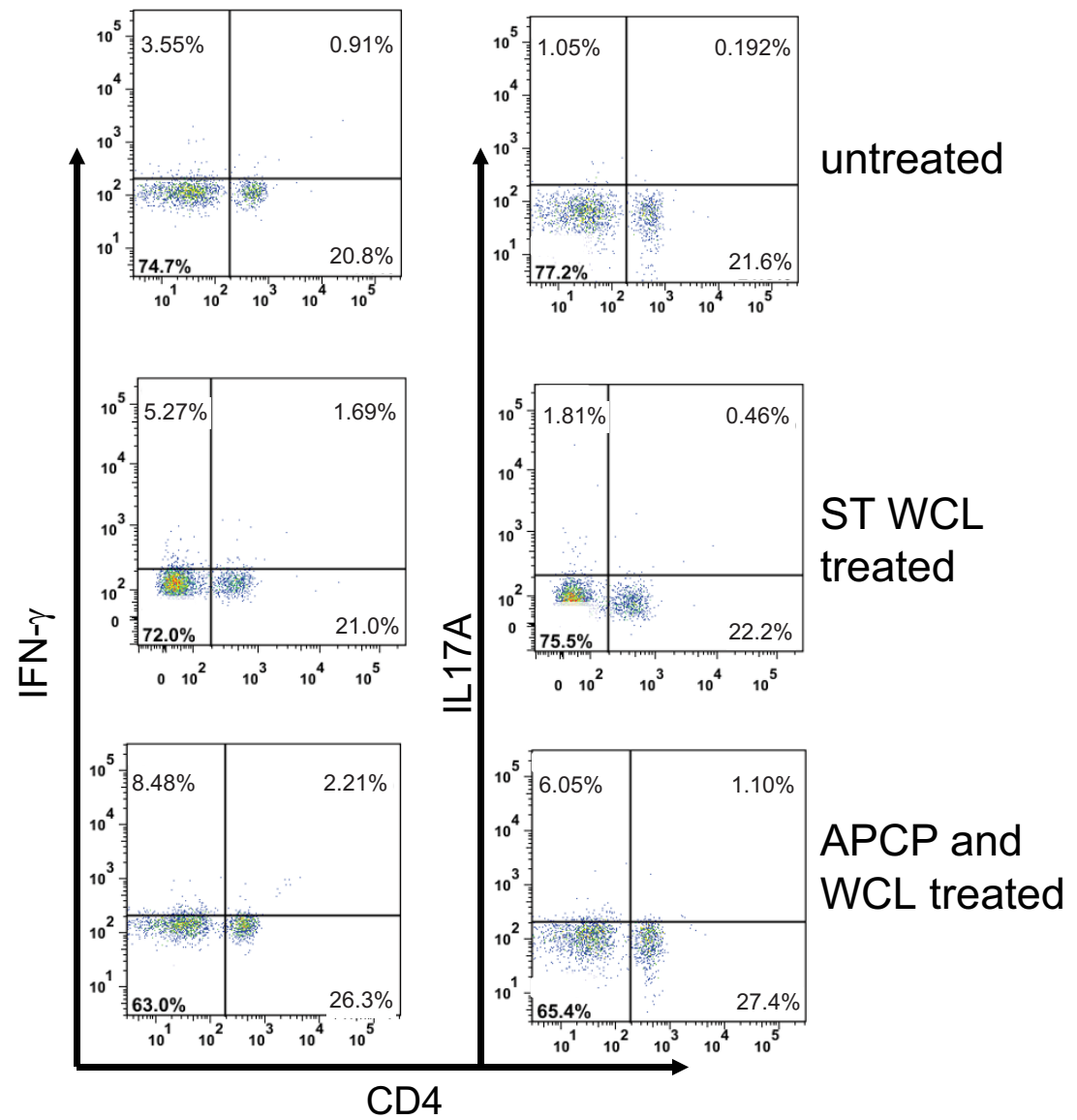

b
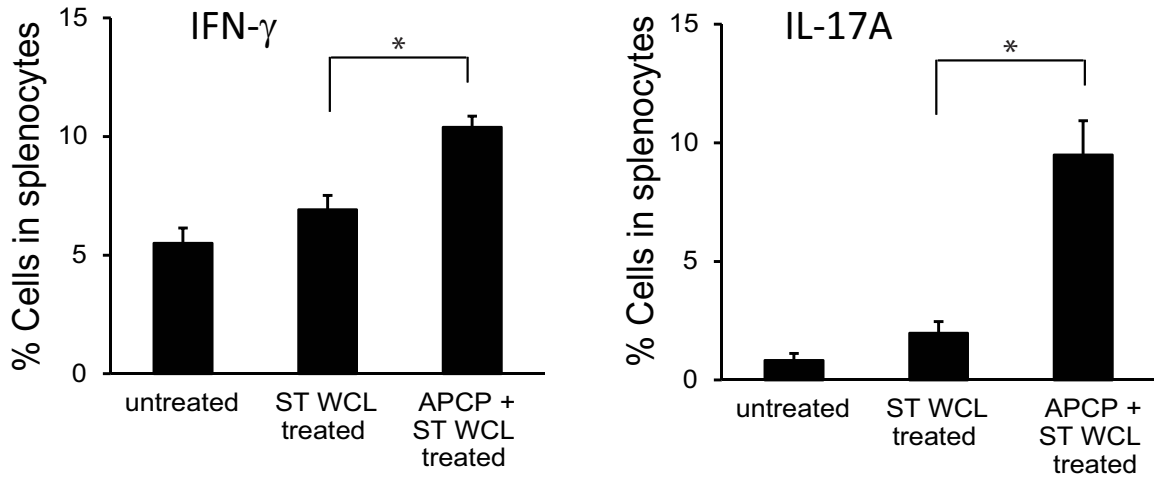

Figure $2 \mid$ Inhibition of CD73 increases IL-17A and IFN- $\gamma$ in CD4 ${ }^{+}$helper T cells. (a), Uninfected wild-type (C57BL/6) mouse derived splenocytes were treated in vitro with ST WCL $((35 \mu \mathrm{g} / \mathrm{ml})$ for $24 \mathrm{~h}$ in the presence or absence of APCP $(100 \mu \mathrm{M})$, a CD73-inhibitor. Splenocytes were surfacestained with PerCp-conjugated anti-mouse $\mathrm{CD}^{+}$, and intracellular-stained with APC-conjugated anti-mouse IL17A, or FITC-conjugated anti-mouse IFN- $\gamma$, using manufacturer's protocol as mentioned in the methods section. Lymphocytes were gated on forward versus side scatter and then analyzed for $\mathrm{CD}^{+}$versus IL17A or IFN- $\gamma$. Summary graph (b) showing the distribution of IL17A, and IFN- $\gamma$ producing cells in the total gated lymphocytes $\left(\mathrm{CD} 4^{+}\right.$cells $+\mathrm{CD} 4^{-}$cells $)$. Figures are from a representative experiment with three mice per group done three times. ${ }^{*}, p<0.05$.

bacterial colonization in the liver and spleen on 13-dpi (Fig. 7b). Of note, infected wild-type mice became extremely sick by 13 days post infection and were euthanized to count bacterial load while $\mathrm{CD} 73^{-1-}$ mice recovered. We monitored infected $\mathrm{CD} 73^{-1-}$ mice until 20-dpi infection and bacterial count were performed.

\section{Discussion}

The control and clearance of intracellular infections require an appropriate host response by the coordinated action of innate and adaptive immunity. In the mouse model of typhoid, clearance of Salmonella requires production of IFN- $\gamma$ by $\mathrm{CD} 4^{+} \mathrm{T}$ cells $s^{10,11,13,34}$ and IL17 from Th17 cells ${ }^{35}$ which in turn plays an important role in amplifying the inflammatory responses in the liver ${ }^{36}$ and gut ${ }^{14}$. Again, the balance between CD4+ Teff cell response and Treg cells can dictate the course of persistent infection ${ }^{15}$. Thus, the disruption of one of the mediators produced by Treg, adenosine, increased Th-1 and Th17 responses from infected $\mathrm{CD} 73^{-1-}$ mouse splenocytes. This notion was supported by the observation that splenocytes stimulated with Salmonella-whole cell lysate produced IFN- $\gamma$ and IL17A, and CD73-inhibition with APCP enhanced this response. The mRNA expression of IFN- $\gamma$, TNF- $\alpha$, and IL1- $\beta$, was significantly increased in the livers of $\mathrm{CD}^{-1-}$ mice in association with an increase in 
a

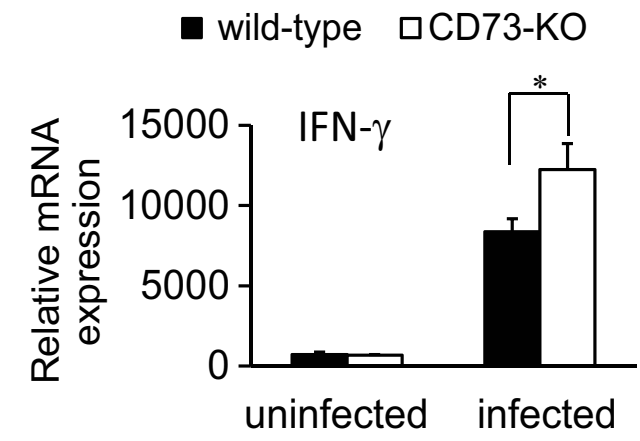

b

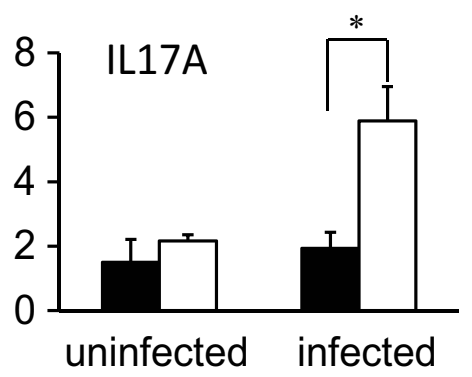

C
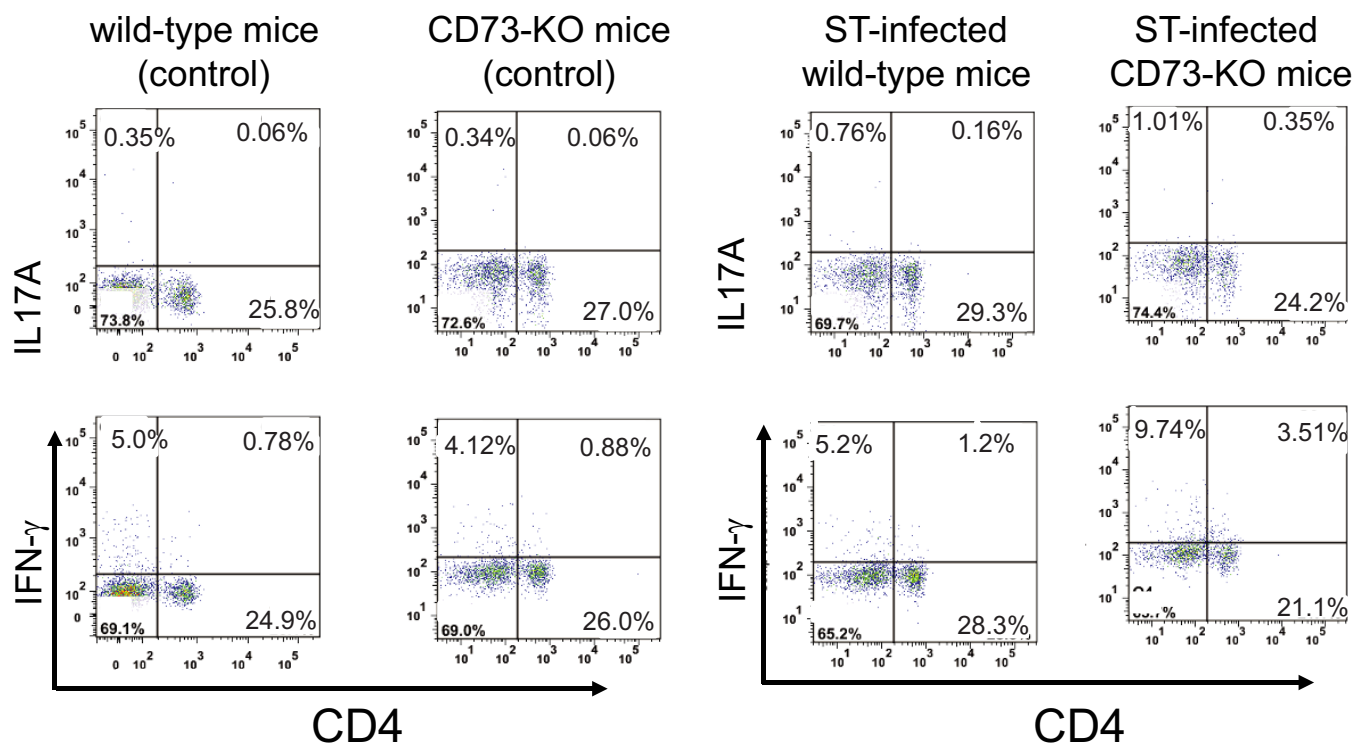

d

wild-type $\square$ CD73-KO
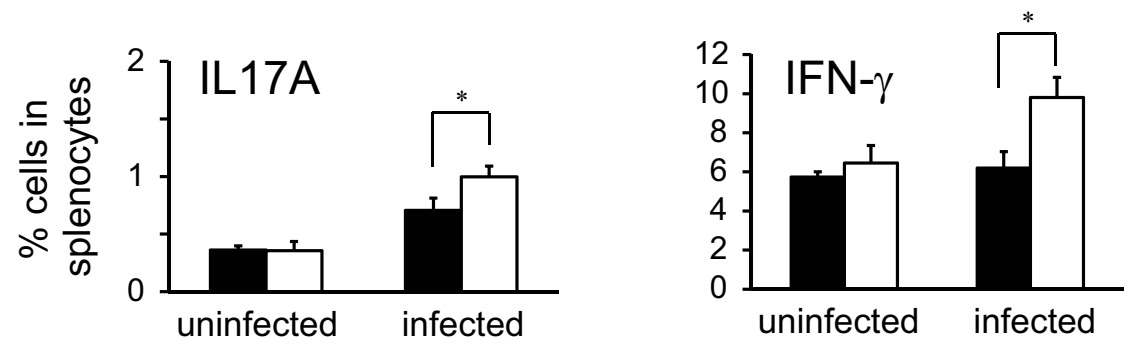

Figure 3 Inflammatory cytokine profile in wild-type and CD73 ${ }^{-/-}$mice following Salmonella infection. Relative mRNA expression of IFN- $\gamma$ (a) and IL-17A (b) in the spleen, 8 days after infection with $1 \times 10^{7}$ CFU of ST. (c), intracellular expression of IL-17A, IFN- $\gamma$, in CD4 ${ }^{+}$helper T cells in isolated splenocytes 8 days after infection. Splenocytes were surface-stained with PerCp-conjugated anti-mouse CD4 ${ }^{+}$, and intracellular-stained with APCconjugated anti-mouse IL17A, or FITC-conjugated anti-mouse IFN- $\gamma$, using manufacturer's protocol as mentioned in the methods section. Lymphocytes were gated on forward versus side scatter and then analyzed for $\mathrm{CD} 4^{+}$versus IL17A or IFN- $\gamma$. Summary graph (d) showing the distribution of IL17A, and IFN- $\gamma$ cells in the total gated splenocytes $\left(\mathrm{CD} 4^{+}\right.$cells $+\mathrm{CD}^{-}$cells). FACS Data are mean \pm SEM from a representative experiment with four mice per group done three times. Relative mRNA data shown are mean \pm SEM from a single experiment performed in triplicate from 3-5 mice, representative of three independent experiments. ${ }^{*}, p<0.05$.

inflammation. CD73-deficient mice also had better survival, lost significantly less body weight, and showed enhanced competence in eliminating Salmonella infection in the liver and spleen compared to wild-type mice.

In addition to the generation of effective anti-bacterial pro-inflammatory responses, infected $\mathrm{CD} 73^{-1-}$ mice had increased liver iNOS mRNA expression. The increase in iNOS is consistent with a report suggesting that the engagement of $\mathrm{A}_{2 \mathrm{~B}} \mathrm{AR}$ agonists suppresses $\mathrm{NO}$ production in LPS-treated RAW 264.7 macrophages ${ }^{37}$. Therefore, adenosine may regulate NO production to influence innate host responses. Further studies examining the role of CD73/adenosine pathways on NO production by macrophages is needed to determine whether these regulatory effects altered Salmonella killing by these cells. 
a
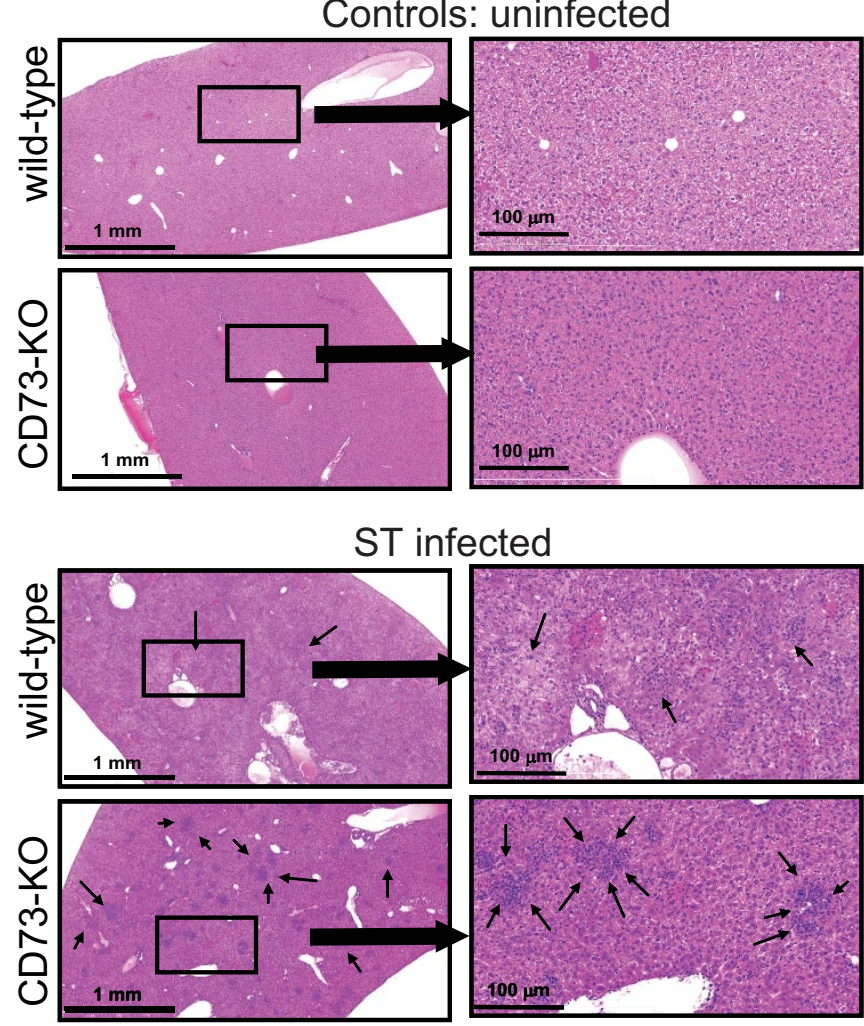

C
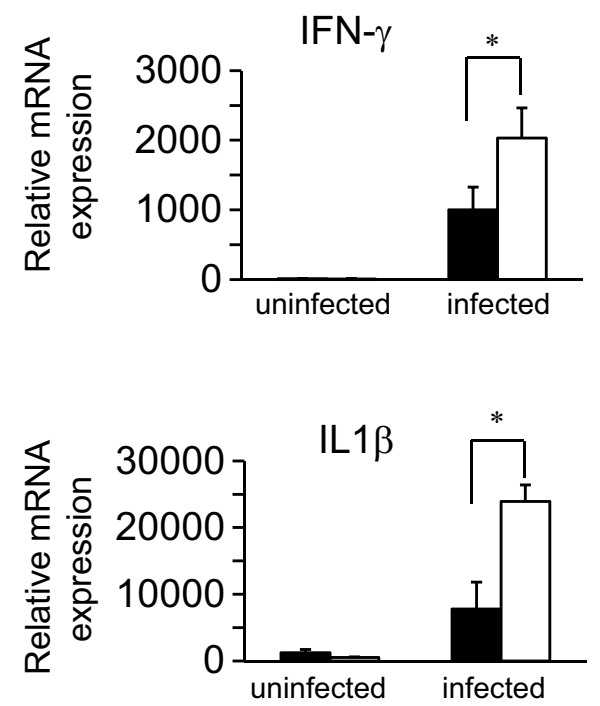

b

wild-type

CD73-KO

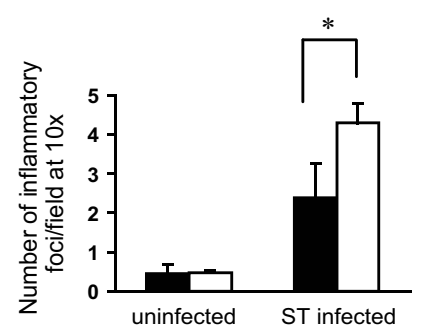

Figure $4 \mid$ Infected CD73 ${ }^{-/-}$mice display enhanced liver inflammatory responses following Salmonella infection. Both wild-type $\left(\mathrm{CD} 73^{+/+}\right)$and $\mathrm{CD}^{-1-}$ mice were orally infected with $1 \times 10^{7} \mathrm{CFU}$ of ST. Mice were euthanized 8 days after infection and the liver tissues were processed for histology. $\mathrm{H} \& \mathrm{E}-$ stained liver sections from representative uninfected wild-type and $\mathrm{CD}^{-1-} 3^{-1}$ mice (a, upper panels); and infected wild-type and CD73 ${ }^{-1-}$ (b, lower panels) mice 8 days after infection. Arrows indicate increased number of inflammatory foci in the liver of the infected CD73 ${ }^{-l-}$ mice which was more abundant than in infected wild-type mice. Only a few scattered mononuclear cells with a normal hepatocyte structure were observed in the uninfected control mice. (b), Quantitative-expression of inflammatory-foci in the wild-type and CD73 ${ }^{-1-}$ mouse liver; quantitative level of liver inflammation was assessed by counting the number of inflammatory-foci in the liver H\&E sections in at least three regions at lower magnification (10 $\times$ ) using $3-8$ mice. (c), Relative mRNA expression of IFN- $\gamma$, TNF- $\alpha$, IL1 $\beta$, and iNOS in liver tissue 8 days after infection. Relative mRNA data shown are from a single experiment performed in triplicate from 3-5 mice, representative of five independent experiments. Data are mean \pm SEM from representative experiment. ${ }^{*}, p<0.05$.

Because CD39 and CD73 are rate-limiting factors for extracellular adenosine generation, the ability of Treg cells to synthesize adenosine from ATP and ADP can contribute significantly to the suppression of effector cells during infection-induced inflammation. In Th cells, the expression of $\mathrm{CD} 39$ and $\mathrm{CD} 73$ by $\mathrm{CD} 4^{+} \mathrm{CD} 25^{\text {+high }}$ Treg cells and the presence of $\mathrm{A}_{2 \mathrm{~A}} \mathrm{AR}$ on activated effector Th cells provide an immunosuppressive loop, whereby Treg generate adenosine that inhibits the function of effector Th cells ${ }^{24,30,32,38}$. Previous findings that Treg cells prepared from mice lacking CD73 fail to regulate inflammation compared to wild-type Treg cells further support the notion that 

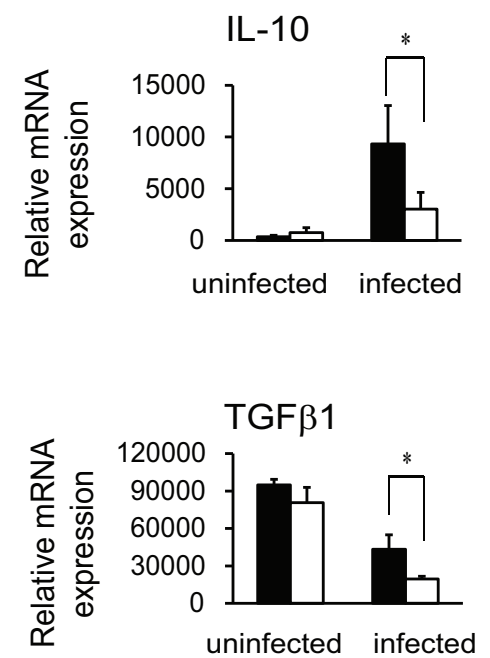
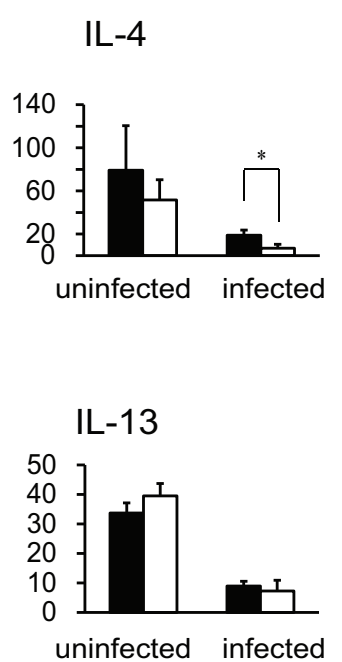

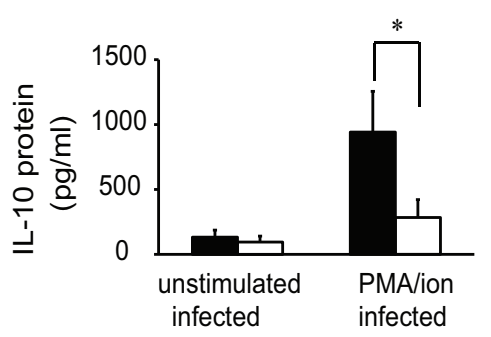

Figure 5 Anti-inflammatory cytokines responses after infection. (a), Relative mRNA expression of anti-inflammatory cytokines (IL-10, IL-4, TGF $\beta$-1, and IL-13) in the spleen tissues, 8 days after infection with $1 \times 10^{7}$ CFU of ST. (b), IL-10 production in the supernatant of ST infected splenocytes. Salmonella-infected mouse derived splenocytes were in vitro activated with PMA/ion for $24 \mathrm{~h}$. Supernatant was collected after $24 \mathrm{~h}$ and measured for IL10 protein by ELISA. Relative mRNA data shown are from a single experiment performed in triplicate from 3-5 mice, representative of five independent experiments. ELISA data are from a representative experiment with 3-4 mice per group done three times. *, $p<0.05$. Data are mean \pm SEM. $*, p<0.05$.

adenosine contributes to the pool of mediators required for optimal Treg cell function ${ }^{26,30}$. In the present study, we observed reduced production of anti-inflammatory cytokines (IL-10/IL-4/TGF- $\beta 1$ ) in infected $\mathrm{CD}_{73^{-1-}}$ mouse tissues, which further suggests that Treg cells from these mice do not produce sufficient levels of IL-10 and TGF- $\beta 1$ to attenuate the pro-inflammatory response.

In addition to our findings that CD73 regulates immunity and exacerbates Salmonellosis, both adenosine $\mathrm{A}_{2 \mathrm{~A}} \mathrm{AR}$ and $\mathrm{A}_{2 \mathrm{~B}} \mathrm{AR}$ are important for governing the morbidity and mortality during poly-
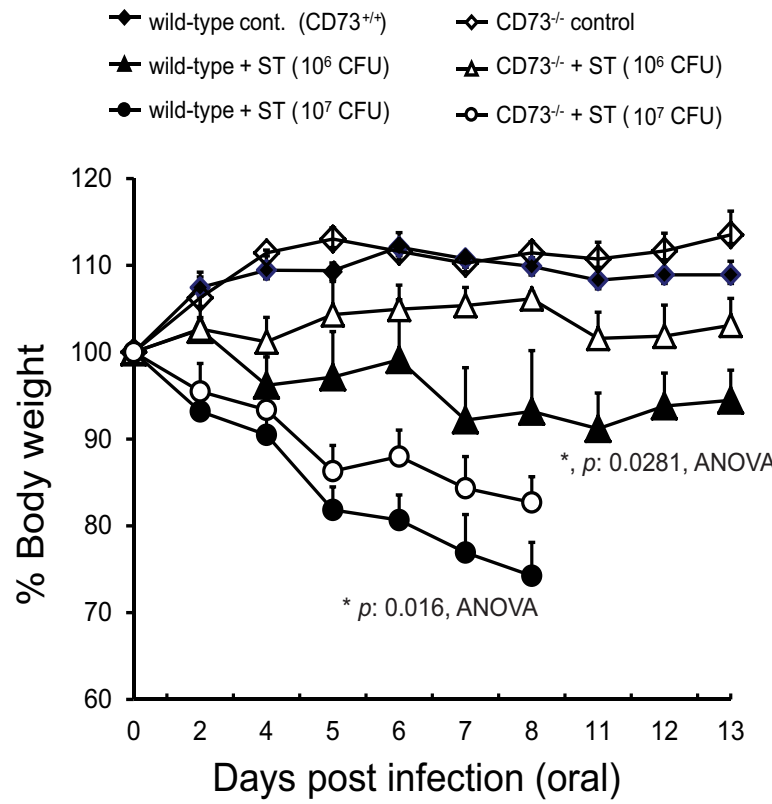

Figure 6 | $\mathrm{CD}^{-/-}$mice lost significantly less body weight compared to the wild-type $\left(\mathrm{CD}^{2} 3^{+/+}\right)$infected mice. Both wild-type $\left(\mathrm{CD}^{+/+}\right)$and $\mathrm{CD} 3^{-1-}$ mice were orally infected with different doses of ST. Body weight was monitored at the indicated times. Data shown are from a representative experiment with four mice per group, done five times. $(*, p<0.02$, ANOVA). microbial sepsis and infection ${ }^{20,39-41}$. Together with our observations, these reports support the notion that adenosine is a significant regulator of disease in mice during infection.

The complexity of adenosine function is illustrated by Hasko et $\mathrm{al}^{42}$ who reported an opposite effect of CD73 during sepsis. In addition, Kolachala el $\mathrm{al}^{43}$ showed that Salmonella infection of $\mathrm{A}_{2 \mathrm{~B}} \mathrm{AR}^{-1-}$ mice led to increased mortality compared to the wild-type counterpart. It is important to note that the pathogenesis of polymicrobial sepsis and different Salmonella models can vary in many ways due to the microbiota in our respective housing facilities. Further, some bacteria adapt to exploit immunosuppressive pathways to increase their own survival ${ }^{44}$, leading to the possibility that adenosine favors the survival of a pathogen if it is present at the correct time or context. In fact, Mohamed et al recently showed that $\mathrm{CD}^{-1-}$ mice are protected from Toxoplasma gondii-induced mortality due to impaired parasite differentiation in the host ${ }^{45}$. The present finding that CD73 suppresses inflammation and impairs bacterial clearance is consistent with a previous report ${ }^{30}$ showing that CD73 inhibition or $\mathrm{A}_{2 \mathrm{~A}} \mathrm{AR}$ deletion $^{18}$ augments pro-inflammatory responses in human Th cells as well as increases gastritis in an animal model of $H$. pylori infection. Moreover, CD73 may mediate noncatalytic functions related to costimulation and/or adhesion ${ }^{46}$. However, the increase in inflammation in infected $\mathrm{CD}_{73^{-1-}}$ mice and the effects of the enzymatic inhibitor APCP observed in the current study favors the hypothesis that the absence of CD73 enhances T cell activation by compromising the synthesis of adenosine rather than disruption of activation signals.

In our study we observed Salmonella infection reduced the expression of both CD39 and CD73 in a tissue, suggesting the host attempts to favor adaptive responses to clear infection. This response might be essential to avoid the suppressive effects due to adenosine generation during $\mathrm{T}$ cell activation ${ }^{38}$. While CD39 and CD73 expression on Treg may decrease in response to infection, the mechanism accounting for this remains unclear. One possibility is that CD73 expression is modulated by the cytokine milieu present during activation by Salmonella infection, for example, the decrease in TGF$\beta 1$ would remove a potent stimulus for CD73 expression ${ }^{38,47}$. However, if this effect is designed to control bacterial burden, it is not as dramatic as the CD73-deficient mice in which the absolute 

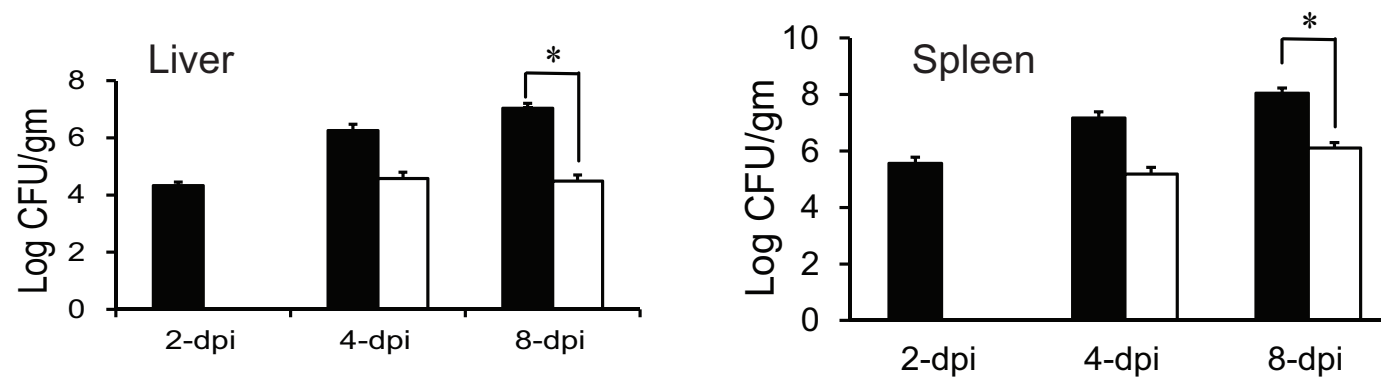

b
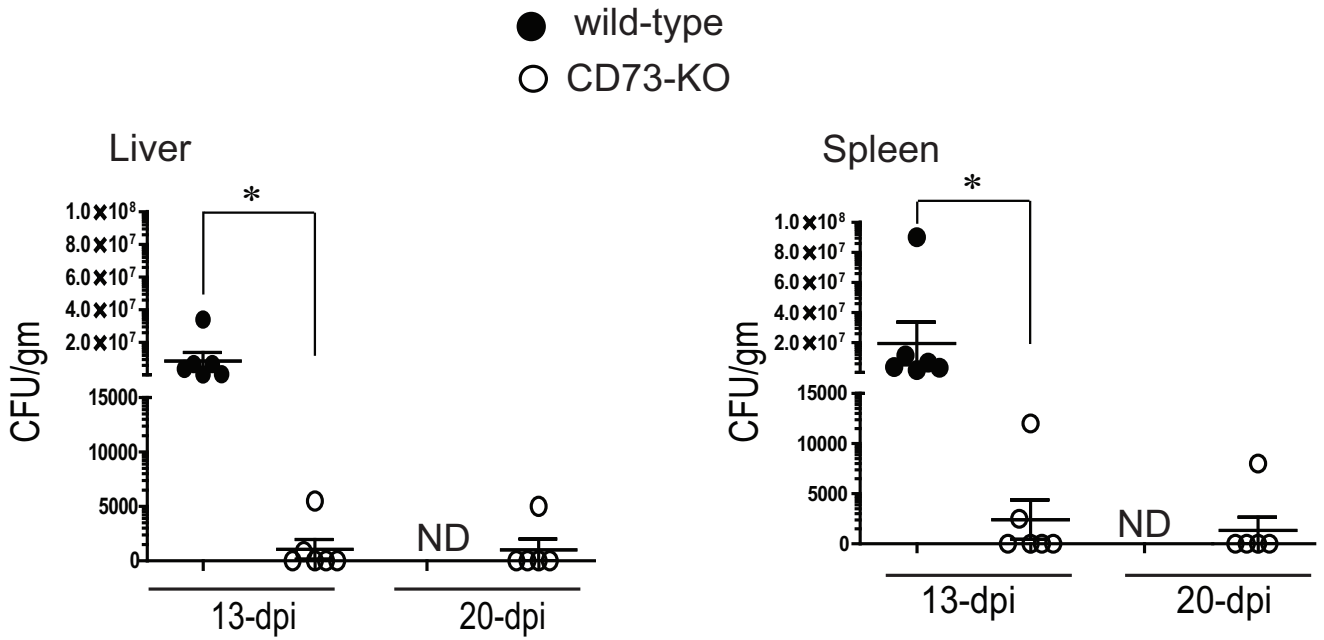

Figure $7 \mid$ Reduction of Salmonella colonization in infected $\mathrm{CD}^{2} 3^{-/-}$mouse liver and spleen. (a), Wild-type and CD73 ${ }^{-1-}$ mice were orally infected with $1 \times 10^{7} \mathrm{CFU}$ Salmonella per mouse. Viable Salmonella counts in the tissue samples were determined at different time points after infection. Data are mean \pm SEM from one experiment with 3-4 mice per group performed at least three times. (b), Viable Salmonella counts in the tissues were determined on 13dpi and 20-dpi. Wild-type and CD73 ${ }^{-1-}$ mice were orally infected with $\sim 2 \times 10^{6}$ CFU Salmonella per mouse. Viable Salmonella counts in the tissue samples of wild-type and $\mathrm{CD}_{73^{-1}}$ mice were determined on 13-days after infection. Also, in the figure, 20-dpi viable Salmonella counts in the tissue samples of $\mathrm{CD}_{73^{-1-}}$ mice were shown. (ND), No viable count done for wild-type mice, as all Salmonella-infected wild-type had to be euthanized due to severe weight loss between 13-15 days post infection. Data are mean \pm SEM from one experiment with 5-6 mice per group performed two times.

disruption of this pathway decreases bacterial burden and increases survival. This is due to the fact that CD73 expression by effector Th cells and other cells might also contribute to the adenosine pool, which serves to limit host responsiveness. In turn, this pool would inhibit the anti-microbial responses and favor infection.

In summary, expression of CD39 and CD73 by Th cells and the enrichment of both enzymes in murine Treg cells suggest that Th cells contribute to local adenosine accumulation and the control of inflammation. Diminished adenosine generation in APCP-treated cells or CD73-deficient mice was associated with an enhanced pro-inflammatory response that reduced the levels of Salmonella colonization upon challenge. These observations support the notion that adenosine production and the ability of adenosine to limit inflammation favors bacterial survival, thereby broadening the impact of infection.

\section{Methods}

Reagents. Adenosine $5^{\prime}$ - $\left(\alpha, \beta\right.$-methylene) diphosphate (APCP) $5^{\prime}$-AMP and NECA, ZM241385 were purchased from Sigma-Aldrich Chemical Co. (St. Louis, MO).

Mice. Wild-type, C57BL/6 $\left(\mathrm{CD} 73^{+/+}\right)$black mice were purchased from The Jackson Laboratory (Bar Harbor, ME). CD73-deficient $\left(\mathrm{CD}^{-1-} 3^{-1}\right)$ mice inbred onto the C57BL/ 6 background were kindly provided by Dr. Linda Thompson ${ }^{48}$.

Ethics statements. This study was carried out in strict accordance with the recommendations in the Guide for the Care and Use of Laboratory Animals of the
National Research Council. The protocol was approved by the Food and Drug Administration-Center for Food Safety and Applied Nutrition-Institutional Animal Care and Use Committee (FDA-CFSAN-IACUC), (Protocol/Permit Number: BFQ $\# 10-002)$. All mice were maintained at the FDA Module-1 animal facility using procedures approved by the FDA-CFSAN-IACUC.

Salmonella growth conditions, ST whole cell lysate preparation. Salmonella enterica serotype Typhimurium (LT-2 strain) was cultured on LB agar plates (BBL, Becton and Dickinson, MD) at $37^{\circ} \mathrm{C}$ for $18 \mathrm{~h}$. The number of bacteria orally inoculated was estimated spectrometrically. To prepare Salmonella LT-2 whole cell lysate (WCL) as an antigen, Salmonella were sonicated and the resulting supernatant was collected.

Salmonella challenge of mice. To establish a primary Salmonella infection, mice were inoculated by gavage with Salmonella LT-2 strain containing $1 \times 10^{6}$ to $1 \times$ $10^{7} \mathrm{CFU}$ of the bacteria. Prior to infection, cage-bedding was exchanged for at least 2 weeks between wild-type (C57BL/6) and $\mathrm{CD}^{2} 3^{-1-}$ mice by mixing soiled beddings (containing fecal materials) from two sources and then redistributing it with the fresh bedding materials. Bedding exchange was performed to equilibrate the colonization of the commensal gut flora between both wild-type and $\mathrm{CD} 73^{-1-}$ mice, which was believed to generate specific gut immune response ${ }^{49}$. In addition, to ensure equal infection (dose), prior to infection, all mice were fasted for approximately 6 hours. Metal wire-flooring was used in the cage for a maximum of 3 days to prevent coprophagia. Mice were monitored daily for clinical signs of disease and body weight was measured. Infected mice that became severely sick were euthanized as par FDACFSAN-IACUC guidelines. Mice that became suddenly sick or died within 3 days of infection without any significant changes in the body weight were not included in the study. 
Histopathology of liver samples. Portions of liver were fixed in Bouin's solution (Ricca Chemical, Arlington, TX), washed with ethanol, embedded in paraffin, cut into 3- to 5- $\mu \mathrm{m}$ sections, and stained with hematoxylin and eosin (H\&E). All H\&E stained slides were scanned and digitally stored using the Nanozoomer (Hamamatsu, Japan) with their NDP-view software (Hamamatsu). Liver inflammation was quantified by counting the number of inflammatory foci defined as a region with mononuclear immune cell infiltrate at $10 \times$ magnification.

Assessment of Salmonella colonization in liver. For quantitative measurement of Salmonella colonization, a portion of liver tissue was homogenized in PBS, and replicate serial 10-fold dilutions were plated in LB agar plates to determine bacterial numbers.

Splenocyte stimulation assay. Murine splenocytes $\left(2 \times 10^{5}\right.$ cell/well or $1 \times 10^{6}$ cell/ well) from uninfected or infected wild-type or CD73-deficient mice were cultured in round bottom 96-well or 24-well flat-bottom tissues culture plates (Costar, Corning) with RPMI medium supplemented with $10 \%$ heat-inactivated fetal bovine serum, $100 \mu \mathrm{g} / \mathrm{ml}$ streptomycin, $100 \mathrm{U} / \mathrm{ml}$ penicillin, and $55 \mu \mathrm{m} 2$-mercaptoethanol at $37^{\circ} \mathrm{C}$ under $5 \% \mathrm{CO}_{2}$. Splenocytes isolated from uninfected mouse were stimulated with Salmonella-WCL $(35 \mu \mathrm{g} / \mathrm{ml})$ in the presence or absence of APCP $(100 \mu \mathrm{M})$, a CD73 enzyme-inhibitor. Splenocytes were stimulated with immobilized $\alpha$-CD3/ $\alpha$-CD28 $(5 \mu \mathrm{g} / \mathrm{ml})$ or PMA/ionomycin $(50 \mathrm{ng} / \mathrm{ml}+500 \mathrm{ng} / \mathrm{ml})$ or with Salmonella-WCL $(35 \mu \mathrm{g} / \mathrm{ml})$ in the presence or absence of APCP $(100 \mu \mathrm{M})$, CD73 enzyme-inhibitor. In some experiments $5^{\prime}$-AMP $(0.5-50 \mu \mathrm{M})$ or NECA (500 nM) or ZM241385 $(500 \mathrm{nM})$ was also used in a similar splenocytes stimulation assay as described earlier $^{18,25}$. Supernatant and cells were collected after $24 \mathrm{~h}$ of incubation and used for ELISAs or multiplex bead array.

Surface and intracellular cell staining and flow cytometry. Isolated splenocytes were washed and resuspended in PBS. Cells were placed on ice and labeled with fluorescein isothiocyanate (FITC)-conjugated anti-mouse $\mathrm{CD} 4^{+}$(BD Pharmingen, CA), allophycocyanin (APC)-conjugated anti-mouse CD25 (BD Pharmingen), phycoerythrin (PE) conjugated anti-mouse CD73 (BD Pharmingen) and PE-Cy7conjugated anti-mouse CD39 (eBiosciences, CA). Intracellular staining of splenocytes was also performed after surface staining in some experiments. For intracellular staining, cultured cells were collected and stimulated with leukocyte activation cocktail (PMA/ionomycin), with BD GolgiPlug (BD Biosciences) according to the manufacturer's protocol, for $4 \mathrm{~h}$. Cells were incubated with FcBlock, stained with anti-CD4 (BD Biosciences), permeabilized, and stained with anti-IL17A (eBiosciences), or anti-IFN- $\gamma$ (eBiosciences), using a Cytofix/Cytoperm kit (BD Biosciences). Cells were also stained with their respective isotype controls as recommended in the manufacturer's protocols for adjusting gates. Samples were assayed with a BD FACSCalibur flow cytometer, and data were analyzed with FlowJo (TreeStar) software.

Cytokine assays. IFN- $\gamma$ and IL-10 concentrations in the supernatants of Salmonella WCL-stimulated cultures were measured by ELISA according to the manufacturer's protocol (BD Biosciences, CA). Similarly IL17A concentration was measured by ELISA according to the manufacturer's protocol (eBiosciences). For some experiments supernatants collected from the culture assays were assayed for Th1 cytokines by use of a multiplex bead array (Bio-Rad, CA) and were analyzed using the Bioplex workstation and associated software (Bio-Plex Manager, version 6.1; Bio$\mathrm{Rad})$.

RNA extraction and Real-time RT-PCR. Total RNA was extracted from liver, spleen, and splenocytes using Qiagen kits (Qiagen, Valencia, CA). In each case RNA was reverse-transcribed to yield cDNA using the $\mathrm{RT}^{2}$ First Strand kit (Qiagen). Transcripts were measured by Real-time RT-PCR and performed in CFX96 RealTime System BioRad (Irvine, CA) using RT2 SYBR Green qPCR and RT ${ }^{2}$ qPCR primers (IFN- $\gamma$ : PPM03121A, TNF- $\alpha$ : PPM03113F, IL-1 $\beta$ : PPM03109E, IL-17A: PPM03023A, IL-13: PPM03021A, IL-10: PPM03017B, IL-4: PPM03013E, TGF- $\beta 1$ : PPM02991A and iNOS: PPM02928B) from SABiosciences Corporation-Qiagen Company (Frederick, MD). The levels of RNA for the target sequences were determined by melting curve analysis using the Bio-Rad CFX manager software (Irvine, CA). Normalized levels of each mRNA were determined using the formula $2^{(\mathrm{Rt}-\mathrm{Et})}$, where Rt is the threshold cycle for the reference gene (GAPDH: PPM02946E, Qiagen) and Et is the threshold cycle for the experimental gene $\left(\Delta \Delta \mathrm{C}_{\mathrm{T}} \text { method }\right)^{50}$. Data are expressed as arbitrary units.

Statistical analysis. Results are expressed as mean \pm SEM. Data were compared by Student's $t$ test (unpaired) or AVOVA, and results were considered significant if $p$ values were less than 0.05 .

1. Butler, T., Islam, A., Kabir, I. \& Jones, P. K. Patterns of morbidity and mortality in typhoid fever dependent on age and gender: review of 552 hospitalized patients with diarrhea. Rev. Infect. Dis. 13, 85-90 (1991).

2. Scallan, E. et al. Foodborne illness acquired in the United States--major pathogens. Emerg. Infect. Dis. 17, 7-15 (2011).

3. Alam, M. S. et al. Role of nitric oxide in host defense in murine salmonellosis as a function of its antibacterial and antiapoptotic activities. Infect. Immun. 70 , $3130-3142(2002)$
4. Santos, R. L. et al. Animal models of Salmonella infections: enteritis versus typhoid fever. Microbes Infect. 3, 1335-1344 (2001).

5. Merrell, D. S. \& Falkow, S. Frontal and stealth attack strategies in microbial pathogenesis. Nature 430, 250-256 (2004)

6. Monack, D. M., Mueller, A. \& Falkow, S. Persistent bacterial infections: the interface of the pathogen and the host immune system. Nat. Rev. Microbiol. 2, 747-765 (2004)

7. Shiloh, M. U. et al. Phenotype of mice and macrophages deficient in both phagocyte oxidase and inducible nitric oxide synthase. Immunity 10, 29-38 (1999).

8. Vazquez-Torres, A., Jones-Carson, J., Mastroeni, P., Ischiropoulos, H. \& Fang, F. C. Antimicrobial actions of the NADPH phagocyte oxidase and inducible nitric oxide synthase in experimental salmonellosis. I. Effects on microbial killing by activated peritoneal macrophages in vitro. J Exp. Med 192, 227-236 (2000).

9. Alam, M. S. et al. Nitric oxide produced in Peyer's patches exhibits antiapoptotic activity contributing to an antimicrobial effect in murine salmonellosis. Microbiol. Immunol 52, 197-208 (2008).

10. Hess, J., Ladel, C., Miko, D. \& Kaufmann, S. H. Salmonella typhimurium aroAinfection in gene-targeted immunodeficient mice: major role of CD4+ TCRalpha beta cells and IFN-gamma in bacterial clearance independent of intracellular location. J Immunol 156, 3321-3326 (1996).

11. Ravindran, R., Foley, J., Stoklasek, T., Glimcher, L. H. \& McSorley, S. J. Expression of T-bet by CD4 T cells is essential for resistance to Salmonella infection. J Immunol 175, 4603-4610 (2005).

12. Eckmann, L., Fierer, J. \& Kagnoff, M. F. Genetically resistant (Ityr) and susceptible (Itys) congenic mouse strains show similar cytokine responses following infection with Salmonella dublin. J Immunol 156, 2894-2900 (1996).

13. Srinivasan, A., Nanton, M., Griffin, A. \& McSorley, S. J. Culling of activated CD4 T cells during typhoid is driven by Salmonella virulence genes. J Immunol 182, 7838-7845 (2009).

14. Godinez, I. et al. T cells help to amplify inflammatory responses induced by Salmonella enterica serotype Typhimurium in the intestinal mucosa. Infection and immunity 76, 2008-2017 (2008).

15. Johanns, T. M., Ertelt, J. M., Rowe, J. H. \& Way, S. S. Regulatory T cell suppressive potency dictates the balance between bacterial proliferation and clearance during persistent Salmonella infection. PLoS pathogens 6, e1001043 (2010).

16. Jantsch, J., Chikkaballi, D. \& Hensel, M. Cellular aspects of immunity to intracellular Salmonella enterica. Immunol Rev. 240, 185-195 (2011).

17. Nikolova, M. et al. CD39/adenosine pathway is involved in AIDS progression. PLoS Pathog. 7, e1002110 (2011).

18. Alam, M. S. et al. A2A adenosine receptor (AR) activation inhibits proinflammatory cytokine production by human $\mathrm{CD} 4+$ helper $\mathrm{T}$ cells and regulates Helicobacter-induced gastritis and bacterial persistence. Mucosal. Immunol 2 232-242 (2009)

19. Drygiannakis, I., Ernst, P. B., Lowe, D. \& Glomski, I. J. Immunological alterations mediated by adenosine during host-microbial interactions. Immunol Res. 50, 69-77 (2011).

20. Belikoff, B. G. et al. A2B adenosine receptor blockade enhances macrophagemediated bacterial phagocytosis and improves polymicrobial sepsis survival in mice. J Immunol 186, 2444-2453 (2011).

21. Sitkovsky, M. V. et al. Physiological control of immune response and inflammatory tissue damage by hypoxia-inducible factors and adenosine A2A receptors. Annu. Rev. Immunol 22, 657-682 (2004).

22. Peng, Z. et al. Ecto-5' -nucleotidase (CD73) -mediated extracellular adenosine production plays a critical role in hepatic fibrosis. FASEB J 22, 2263-2272 (2008).

23. Hasko, G., Linden, J., Cronstein, B. \& Pacher, P. Adenosine receptors: therapeutic aspects for inflammatory and immune diseases. Nat. Rev. Drug Discov. 7, 759-770 (2008).

24. Deaglio, S. et al. Adenosine generation catalyzed by CD39 and CD73 expressed on regulatory T cells mediates immune suppression. J. Exp. Med. 204, 1257-1265 (2007).

25. Kobie, J. J. et al. T regulatory and primed uncommitted CD4 T cells express CD73, which suppresses effector CD4 T cells by converting 5 '-adenosine monophosphate to adenosine. J Immunol 177, 6780-6786 (2006).

26. Ernst, P. B., Garrison, J. C. \& Thompson, L. F. Much ado about adenosine: adenosine synthesis and function in regulatory T cell biology. J Immunol 185, 1993-1998 (2010).

27. Rad, R. et al. CD25+/Foxp3 + T cells regulate gastric inflammation and Helicobacter pylori colonization in vivo. Gastroenterology 131, 525-537 (2006)

28. Mendez, S., Reckling, S. K., Piccirillo, C. A., Sacks, D. \& Belkaid, Y. Role for $\mathrm{CD} 4(+) \mathrm{CD} 25(+)$ regulatory $\mathrm{T}$ cells in reactivation of persistent leishmaniasis and control of concomitant immunity. J Exp. Med 200, 201-210 (2004).

29. Walther, M. et al. Upregulation of TGF-beta, FOXP3, and CD4+CD25+ regulatory $\mathrm{T}$ cells correlates with more rapid parasite growth in human malaria infection. Immunity 23, 287-296 (2005).

30. Alam, M. S. et al. CD73 is expressed by human regulatory T helper cells and suppresses proinflammatory cytokine production and Helicobacter felis-induced gastritis in mice. J Infect. Dis. 199, 494-504 (2009).

31. Synnestvedt, K. et al. Ecto-5' -nucleotidase (CD73) regulation by hypoxiainducible factor- 1 mediates permeability changes in intestinal epithelia. J Clin Invest 110, 993-1002 (2002). 
32. Kobie, J. J. et al. T regulatory and primed uncommitted CD4 T cells express CD73, which suppresses effector CD4 T cells by converting 5 '-adenosine monophosphate to adenosine. J. Immunol. 177, 6780-6786 (2006).

33. Borsellino, G. et al. Expression of ectonucleotidase CD39 by Foxp3 + Treg cells: hydrolysis of extracellular ATP and immune suppression. Blood 110, 1225-1232 (2007).

34. Ramarathinam, L., Niesel, D. W. \& Klimpel, G. R. Ity influences the production of IFN-gamma by murine splenocytes stimulated in vitro with Salmonella typhimurium. J Immunol 150, 3965-3972 (1993).

35 . Geddes, K. et al. Identification of an innate T helper type 17 response to intestinal bacterial pathogens. Nat. Med 17, 837-844 (2011)

36. Sebastiani, G. et al. Host immune response to Salmonella enterica serovar Typhimurium infection in mice derived from wild strains. Infect. Immun. 70, 1997-2009 (2002)

37. Hasko, G. et al. Adenosine receptor agonists differentially regulate IL-10, TNFalpha, and nitric oxide production in RAW 264.7 macrophages and in endotoxemic mice. J Immunol 157, 4634-4640 (1996).

38. Regateiro, F. S., Cobbold, S. P. \& Waldmann, H. CD73 and adenosine generation in the creation of regulatory microenvironments. Clin Exp. Immunol 171, 1-7 (2013).

39. Nemeth, Z. H. et al. Adenosine A2A receptor inactivation increases survival in polymicrobial sepsis. Journal of immunology 176, 5616-5626 (2006).

40. Warren, C. A. et al. Contribution of adenosine A(2B) receptors in Clostridium difficile intoxication and infection. Infect. Immun. 80, 4463-4473 (2012).

41. Barletta, K. E., Cagnina, R. E., Burdick, M. D., Linden, J. \& Mehrad, B. Adenosine $\mathrm{A}(2 \mathrm{~B})$ receptor deficiency promotes host defenses against gram-negative bacterial pneumonia. Am. J Respir. Crit. Care Med 186, 1044-1050 (2012).

42. Hasko, G. et al. Ecto-5'-nucleotidase (CD73) decreases mortality and organ injury in sepsis. J Immunol 187, 4256-4267 (2011).

43. Kolachala, V. L. et al. A2B adenosine receptor gene deletion attenuates murine colitis. Gastroenterology 135, 861-870 (2008).

44. Thammavongsa, V., Kern, J. W., Missiakas, D. M. \& Schneewind, O. Staphylococcus aureus synthesizes adenosine to escape host immune responses. J Exp. Med 206, 2417-2427 (2009).

45. Mahamed, D. A., Mills, J. H., Egan, C. E., Denkers, E. Y. \& Bynoe, M. S. CD73 generated adenosine facilitates Toxoplasma gondii differentiation to long-lived tissue cysts in the central nervous system. Proc. Natl. Acad. Sci. U. S A 109, 16312-16317 (2012)

46. Resta, R., Yamashita, Y. \& Thompson, L. F. Ecto-enzyme and signaling functions of lymphocyte CD73. Immunol Rev. 161, 95-109 (1998).
47. Regateiro, F. S. et al. Generation of anti-inflammatory adenosine by leukocytes is regulated by TGF-beta. Eur. J Immunol 41, 2955-2965 (2011).

48. Thompson, L. F. et al. Crucial role for ecto-5' -nucleotidase (CD73) in vascular leakage during hypoxia. J Exp. Med 200, 1395-1405 (2004).

49. Ivanov, I. I. et al. Specific microbiota direct the differentiation of IL-17-producing T-helper cells in the mucosa of the small intestine. Cell Host Microbe 4, 337-349 (2008).

50. Livak, K. J. \& Schmittgen, T. D. Analysis of relative gene expression data using real-time quantitative PCR and the 2(-Delta Delta C(T)) Method. Methods 25, 402-408 (2001)

\section{Acknowledgments}

This research was supported by the intramural research program for the Center for Food Safety and Applied Nutrition, U.S. Food and Drug Administration. The authors are gratefu to Dr. Linda Thompson for providing us with the CD73-deficient mouse breeding pairs.

\section{Author contributions}

M.S.A., P.B.E. and K.W. conceived and designed the experiments. M.S.A., J.K., P.M., D.G. and E.B. performed the experiments. M.S.A., J.K., P.B.E., M.P., V.C., D.G., M.C., E.B. and K.W. analyzed the data. M.S.A., J.K., P.M., V.C., D.G., M.C., E.B. and K.W. contributed reagents/materials/analysis tools. M.S.A., P.B.E. and K.W. wrote the paper. All authors reviewed and approved the manuscript.

\section{Additional information}

Supplementary information accompanies this paper at http://www.nature.com/ scientificreports

Competing financial interests: The authors declare no competing financial interests.

How to cite this article: Alam, M.S. et al. Ecto-5'-Nucleotidase (CD73) Regulates Hos Inflammatory Responses and Exacerbates Murine Salmonellosis. Sci. Rep. 4, 4486; DOI:10.1038/srep04486 (2014)

(c) (i) (2) (2) This work is licensed under a Creative Commons Attributionvisit http://creativecommons.org/licenses/by-nc-sa/3.0 